\title{
Costs of Chronic Hepatitis B patients in a developing country
}

\author{
Chuenrutai Yeekian ${ }^{1}$, Punnee Pitisuttithum ${ }^{2}$ \\ 1. Nursing Department, Queen Savang Vadhana Memorial Hospital, The Thai Red Cross Society, Chon Buri, Thailand. \\ 2. Faculty of Tropical Medicine, Mahidol University, Bangkok, Thailand.
}

Correspondence: Chuenrutai Yeekian. Address: 290 Jermjompol Road, Queen Savang Vadhana Memorial Hospital, The Thai Red Cross Society, Chon Buri, Thailand. Email: jayeekian88@live.com

Received: May 6, 2014

Accepted: July 17, $2014 \quad$ Online Published: July 23, 2014

DOI : $10.5430 /$ jnep.v4n9p128

URL: http://dx.doi.org/10.5430/jnep.v4n9p128

\section{Abstract}

Background: Studying the costs of Chronic Hepatitis B in the different severe liver disease aids evaluation of the cost impact of treatment.

Objectives: To assess and compare costs of CHB patients with severe and non-severe liver diseases.

Methods: This is a prospective study conducted among 152 adult CHB patients at an out-patient setting of a general hospital in Thailand. The total cost comprised of direct medical cost, direct non-medical cost and indirect cost at a one year follow up. Severity of liver disease was assessed by the Chronic Liver Disease Questionnaire (CLDQ) at initial day, $6^{\text {th }}$ and $12^{\text {th }}$ month of follow up.

Results: Mean (SD) age of the patients was 41.6 (11.8) years. Mean (SD) total cost per year of CHB patients with severe and non-severe liver diseasesgroups were United State Dollar (USD) 1,876.5 $(1,481.9)$ and 1,360.0 $(2,278.0)$. There was no difference of total cost and direct medical costs between the two groups. However, compared to the non-severe liver disease, the severe liver disease had significant mean (SD) direct non-medical costs (USD 238.8 (289.6) vs. 117.0 (160.8), $p=.027$ ), and indirect cost (USD 584.2 (794.0) vs. $196.7(520.2), p=.012)$ more than the non-severe liver disease.

Conclusions: For CHB patients with severe liver disease, physical illness affects their worry and emotional functions, and the disease incur costs more than the non-severe liver disease. CHB-related diseases could result to productivity loss especially in patients with cirrhosis.

\section{Key words}

Chronic hepatitis B, Costs, Chronic Liver Disease Questionnaire

\section{I ntroduction}

Hepatitis B virus (HBV) is one of the majority widespread sources of chronic liver infection in human worldwide. According to Lavanchy (2004), $15 \%-40 \%$ of chronic hepatitis B patients will develop liver failure or hepatocellular carcinoma ${ }^{[1]}$. Several studies have shown that CHB imposes substantial costs on patients, families and the society ${ }^{[2-7]}$. The costs increase dramatically as the disease progress to more advanced stages ${ }^{[3,4,7]}$. Also, evidence from economic studies contributes to the understanding of potential benefits to society from allocating more resources to prevention and treatment of HBV infections in highly endemic countries such as China, Korea, Hong Kong, and Singapore ${ }^{[3-7]}$. However, there is no 
study of costs together with a prospective assessment of severity of liver disease in CHB patients. Also, few cost studies included indirect cost.

In Thailand, CHB is one of the most common causes of cirrhosis. In 2005, about $2 \%-7 \%$ of Thai adults were infected with HBV ${ }^{[8]}$. Currently, the antiviral drugs (ARV) were recommended for treatment of CHB in Thailand ${ }^{[9]}$. However, the lifelong treatment with ARV and regular monitoring in CHB patients will incur considerable healthcare resources ${ }^{[10]}$. The assessment of changes in the clinical course of CHB diseases during ARV is one of the key points for the management of $\mathrm{CHB}^{[11]}$. Consequently, the study of costs in CHB patients with severe liver disease treated with ARV may demonstrate benefits of ARV on CHB management.

\section{Methods}

This research project was approved by the Ethics Committee of the Faculty of Tropical Medicine, Mahidol University, and Queen Savang Vadhana Memorial Hospital, Chon Buri province, Thailand. The sample size was calculated based on a mean CLDQ score of 150 Thai chronic liver diseases patients from the study by Sobhonslidsuk et al. ${ }^{[12]}$ (mean \pm standard deviation (SD) $=4.75 \pm 1.2$ out of 7 scores) those were adjusted them up as 7 scores is equal to one hundred scores (67.86 \pm 17.14 scores). The formula is $n=z^{2} \mathrm{SD}^{2} / \mathrm{d}^{2}$, whereas: $n=$ sample size, $z=1.96$ (95\% Confidence Interval), $S D=$ standard deviation, $d=$ margin of error in estimating mean or effect size.

By the formula, the estimated sample size was 54 participants. However, for the reliability of costs' analysis, there were 152 participants in this study.

Participants were all CHB patients of the Queen Savang Vadhana Memorial Hospital out-patient setting from November 2011 to April 2013. Inclusion criteria were 1) male or female aged 18 years and over, 2) criteria for diagnosis and/ or treatment bases on Thailand Consensus Recommendations for Management of Chronic Hepatitis B and C 2009 [9], 3) participant's willingness to participate voluntarily, and able to provide written informed consent. Exclusion criteria were severe uncontrolled disease involving other organs (heart, kidney, lung) except the liver.

The total cost including the costs of hospitalization comprised direct medical costs, direct non-medical costs, and indirect cost each case per year. Direct medical costs and routine service cost with capital costs were collected from the hospital database, and the direct non-medical cost was collected from patients' self reporting. The indirect cost was assessed in term of work productivity loss. Patients were requested for degree of impairment from the least 0 score to the most 10 scores that were applied to percent multiplied with patients' salary.

Severity of liver disease was assessed by CLDQ three times at initial day (D0), $6^{\text {th }}$ month (M6), and $12^{\text {th }}$ (M12) of follow up. CLDQ reflects health in patients' perspective with a high rate of internal consistency $(>0.79)^{[13]}$ with discriminant validity. It has 29 items in 6 domains: abdominal symptoms (AB), fatigue (FA), systemic symptoms (SY), activity (AC), emotional function (EM) and worry (WO) ${ }^{[14]}$. Its answers result in a seven-point Likert scales with one score means "all of the time" or the most impairment to seven scores mean "none of the time" or the least impairment; therefore, the higher score indicates the better health. It had been translated from the original version to Thai language by Sobhonslidsuk et al. ${ }^{[12]}$. The Chronbach's alpha of the overall Thai CLDQ scores was $0.96^{[12]}$. In this study, CLDQ was applied by the patients' self-administering and its reliability by split-half Cronbach's alpha was 0.82 . The patients were divided into two groups including severe and non-severe liver disease by mean CLDQ score of all patients.

To analyze the effects of ARV treatment on indirect cost and CHB diseases, the patients in severe liver disease group were divided into patients with and without ARV subgroups and classified by their clinical characteristics at D0: HBsAg carrier, uncomplicated CHB, impaired liver function, and cirrhosis/ HCC. Also, the percent of productivity at M12 was compared with D0, and categorized into increasing, stable, and decreasing.

The descriptive statistics were provided with mean (SD) or number (\%) as appropriate. The statistics used for comparing frequencies and mean score between the two groups were chi-square and unpaired $t$-test. For comparing frequencies and 
mean score within group among D0, M6, and M12, the statistics used were Friedman K related test, and Cochran's Q. A $p$ value less than 0.05 was considered as statistically significant. Data was analyzed with SPSS version 17.

\section{Results}

There were 152, 140, and 129 CHB patients participated at D0, M6, and M12. Overall mean (SD) CLDQ score at initial day was 5.5 (0.9) scores; therefore, the patients were divide into the severe liver disease group (CLDQ $<5$ scores) and non-severe liver disease group (CLDQ $\geq 5$ scores) groups. In the severe liver disease group, number of patients at D0, M6, and M12 were 38, 38, and 33, respectively. Their percent loss at M6 and cumulative percent loss at M12 were 0.0 and 13.1. In the non-severe liver disease group, number of patients at D0, M6, and M12 were 114, 102, and 96, respectively. Their percent loss at M6 and cumulative percent loss at M12 were 10.5 and $15.8 \%$.

Overall, mean (SD) age was 41.6 (11.8) years with half were male (53.5). Majority were employees (67.4\%) having mean (SD) salary per month USD 507.4 (1032.5), and had health security (95.3\%). Among patients, 27cases (20.9\%) developed to cirrhosis and HCC. Nearly half (43.4\%) were treated with ARV for hepatitis B infection, and these patients had mean (SD) 22.8 (17.8) months for ARV treatment. Majority (85.7\%) of ARV were tenofovir and lamivudine. All liver biomarkers were in normal level. Compared to the non-severe liver disease group, the severe liver disease group had significantly greater mean (SD) age (45.4 (12.4) vs. 39.6 (11.0), $p=.008)$, lesser mean (SD) albumin (4.0 (0.6) vs. 4.2 (0.5), $p=.042$ ), and higher number (\%) of patients with cirrhosis/HCC (12 (31.6) vs. $59(51.8), p=.048)$ (see Table 1).

Table 1. Comparison of baseline socio-demographic and clinical characteristics between the severe and non-severe liver disease groups

\begin{tabular}{|c|c|c|c|c|}
\hline Parameters & Overall $(n=152)$ & Severe liver disease $(n=38)$ & Non-severe liver disease $(n=114)$ & $\boldsymbol{P}$ \\
\hline \multicolumn{5}{|l|}{ Baseline socio-demographic } \\
\hline Age, mean $(\mathrm{SD})$ years & $41.1(11.6)$ & $45.4(12.4)$ & $39.6(11.0)$ & $.008^{*}$ \\
\hline Male gender, number $(\%)$ & $83(54.6)$ & $18(47.4)$ & $65(57.0)$ & .301 \\
\hline Employee, number (\%) & $105(69.1)$ & $25(65.8)$ & $80(70.2)$ & .612 \\
\hline Salary, mean (SD) USD & $494.8(955.1)$ & $659.6(1817.8)$ & $439.9(353.4)$ & .464 \\
\hline Had health security, number (\%) & $141(92.8)$ & $36(94.7)$ & $105(92.1)$ & .588 \\
\hline $\begin{array}{l}\text { Had presence of other diseases } \\
\text { except liver disease, number }(\%)\end{array}$ & $64(42.1)$ & $19(50.0)$ & $45(39.5)$ & .255 \\
\hline \multicolumn{5}{|l|}{ Baseline clinical characteristics } \\
\hline Cirrhosis/HCC, number (\%) & $31(20.4)$ & $12(31.6)$ & $19(16.7)$ & $.048^{*}$ \\
\hline $\begin{array}{l}\text { ARV for hepatitis B infection, } \\
\text { number }(\%)\end{array}$ & $84(55.3)$ & $24(63.2)$ & $60(52.6)$ & .258 \\
\hline Months of treated ARV, mean (SD) & $\begin{array}{l}22.3(18.0) \\
(n=84)\end{array}$ & $\begin{array}{l}23.8(23.4) \\
(n=24)\end{array}$ & $\begin{array}{l}21.7(15.4) \\
(n=60)\end{array}$ & .637 \\
\hline Log HBV DNA, mean (SD) IU/ml & $\begin{array}{l}5.6(34.1) \\
(n=124)\end{array}$ & $\begin{array}{l}2.7(2.2) \\
(n=32)\end{array}$ & $\begin{array}{l}6.7(36.8) \\
(n=92)\end{array}$ & .542 \\
\hline HBeAg-negative, number (\%) & $80(52.6)$ & $21(55.3)$ & $59(51.8)$ & .708 \\
\hline $\mathrm{ALT}$, mean $(\mathrm{SD}) \mathrm{U} / 1$ & $36.4(39.8)$ & $35.8(21.3)$ & $36.6(44.4)$ & .911 \\
\hline AST, mean (SD) U/1 & $33.9(30.10)$ & $28.9(16.8)$ & $35.6(33.2)$ & .238 \\
\hline Alkaline phosphates, mean (SD) U/1 & $80.3(37.6)$ & $89.1(44.2)$ & $77.3(34.8)$ & .096 \\
\hline $\begin{array}{l}\text { Alpha-fetoprotein, mean (SD) } \\
\mathrm{ng} / \mathrm{ml}\end{array}$ & $\begin{array}{l}11.7(60.3) \\
(n=136)\end{array}$ & $\begin{array}{l}9.7(34.7) \\
(n=36)\end{array}$ & $\begin{array}{l}12.4(67.3) \\
(n=100)\end{array}$ & .822 \\
\hline Total bilirubin, mean (SD) mg/dl & $0.7(0.6)$ & $0.8(0.8)$ & $0.7(0.5)$ & .536 \\
\hline Albumin, mean (SD) g\% & $4.2(0.5)$ & $4.0(0.6)$ & $4.2(0.5)$ & $.042 *$ \\
\hline INR, mean $(\mathrm{SD})$ & $1.0(0.1)$ & $1.1(0.2)$ & $1.0(0.1)$ & .082 \\
\hline Hematocrit, mean (SD) g\% & $39.0(4.8)$ & $37.7(5.5)$ & $39.4(4.5)$ & .068 \\
\hline
\end{tabular}


Regarding costs, mean (SD) total cost per year of the severe and non-severe liver disease groups were USD 1,876.5 $(1,481.9)$ and $1,360.0(2,278.0)$. There was no difference of total cost and direct medical cost between the two groups. However, the severe liver disease group had significant higher mean (SD) direct non-medical cost per year, and indirect cost per year from work productivity loss than the non-severe liver disease group (direct non-medical cost per year USD 238.8 (289.6) vs. 117.0 (160.8), $p=.027$; indirect cost USD 584.2 (794.0) vs. 196.7 (520.2), $p=.012$ ). For subgroups of direct medical and direct non-medical cost per year, the severe liver disease group had significant higher mean (SD) laboratory and supplementary cost than the non-severe liver disease group (laboratory cost USD 206.4 (132.1) vs. 159.9 (83.3), $p=.020$; supplementary cost USD 120.5 (216.7) vs. 44.9 (141.2), $p=.024)$. Nutrition supplements used included, vitamin, Ling zhi, tumaric, drumstic tree, and others. Data are shown in Table 2.

Table 2. Comparison of costs between the severe and non-severe liver disease groups

\begin{tabular}{|c|c|c|c|c|}
\hline Costs & $\begin{array}{l}\text { Overall } \\
(n=129)\end{array}$ & $\begin{array}{l}\text { Severe liver disease } \\
(n=33)\end{array}$ & $\begin{array}{l}\text { Non-severe liver disease } \\
(n=96)\end{array}$ & $\boldsymbol{P}$ \\
\hline Total cost & $1,492.1(2,109.9)$ & $1,876.5(1,481.9)$ & $1,360.0(2,278.0)$ & .227 \\
\hline Direct medical costs & $1,048.1(1,770.9)$ & $1,053.3(1,129.9)$ & $1,046.3(1,948.1)$ & .984 \\
\hline $\mathrm{ARV}$ cost & $454.3(781.6)$ & $490.4(861.3)$ & $441.9(756.7)$ & .760 \\
\hline $\begin{array}{l}\text { Other medication } \\
\text { cost excluded ARV }\end{array}$ & $235.6(1,244.5)$ & $147.7(322.1)$ & $265.9(1,431.2) \dagger$ & .640 \\
\hline Laboratory cost & $171.8(99.7)$ & $206.4(132.1)$ & $159.9(83.3)$ & $.020^{*}$ \\
\hline Radiology cost & $69.6(107.1)$ & $64.5(40.4)$ & $71.4(122.0)$ & .750 \\
\hline Routine service cost & $116.8(300.0)$ & $144.5(409.1)$ & $107.3(254.0)$ & .541 \\
\hline Direct non-medical care costs & $148.1(207.4)$ & $238.8(289.6)$ & $117.0(160.8)$ & $.003^{*}$ \\
\hline Supplementary expense & $64.2(166.2)$ & $120.5(216.7)$ & $44.9(141.2)$ & $.024 *$ \\
\hline Caregiver expense & $16.8(45.3)$ & $29.5(57.3)$ & $12.4(39.7)$ & .060 \\
\hline Transport expense & $15.1(14.4)$ & $18.7(16.4)$ & $13.8(13.5)$ & .094 \\
\hline Food expense & $9.8(9.5)$ & $11.6(12.5)$ & $9.2(8.2)$ & .202 \\
\hline $\begin{array}{l}\text { Labor cost loss for } \\
\text { hospital care }\end{array}$ & $42.2(88.8)$ & $58.4(164.5)$ & $36.6(37.2)$ & .225 \\
\hline Indirect cost & $295.8(622.3)$ & $584.2(794.0)$ & $196.7(520.2)$ & $.002 *$ \\
\hline
\end{tabular}

${ }^{*} p<.05 ; \dagger$ There was 1 HCC case with other medication cost USD 12,904.3, and there were 9 cases cirrhosis/HCC, HIV-HBV co-infections and CHB with gastric ulcer.

Abbreviations: ARV, antiviral therapy for hepatitis B infection; QOL, quality of life.Note. 30.63Baht/1 USD (Bank of Thailand, 2008)

When compared CLDQ scores within group among D0, M6, M12 of the severe and non-severe liver disease groups, the non-severe liver disease group, mean (SD) scores of all domains significantly increased at M6 and M12 accept abdominal symptom domain as shown in Figure 1. At D0, from full CLDQ score ( 7 scores), the most three impairment domains of severe liver disease group were worry (Mean (SD) 3.7 (1.0) scores), fatigue (Mean (SD) 3.7 (1.0) scores), and abdominal symptom (Mean (SD) 4.0 (1.5) scores).

Figure 1. Comparison of CLDQ scores in each domain within group among D0, M6, and M12 of the severe and non-severe liver disease groups

${ }^{*} p<.05,{ }^{* *} p<.01$; Abbreviations: AB, abdominal symptoms; AC, activity; CLDQ, Chronic Liver Disease Questionnaire; CLDQ; D0, Day zero; EM, emotional function; FA, fatigue; M6, $6^{\text {th }}$ month of follow up; M12, $12^{\text {th }}$ month of follow up; SD, Standard Deviation; SY, systemic symptoms; WO, worry.

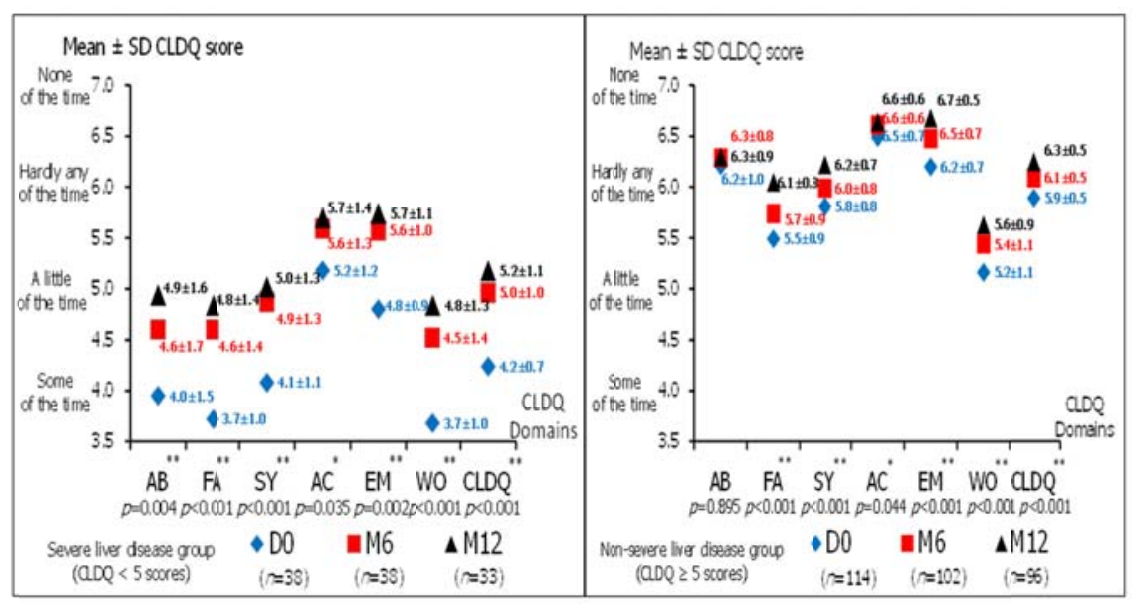

Published by Sciedu Press 
For the effects of ARV treatment on indirect cost and CHB diseases (see Figure 2), in the severe liver disease with ARV group, of 17 cases, four cases were lost to follow up with two cases unable to work, one death, and one lost contact. The other 3 cases of cirrhosis/HCC had productivity stable at $100 \%$. Also, impaired liver function had increasing, stable and decreasing productivity at $25.0 \%, 50.0 \%$ and $25.0 \%$. For those impaired liver function without ARV, the patients had stable productivity at $100.0 \%$. With ARV, uncomplicated CHB had increasing, stable and decreasing productivity at $37.5 \%, 37.5 \%$ and $25.0 \%$, respectively. For those uncomplicated CHB without ARV, the patients had increasing and stable at $20.0 \%$ and $80.0 \%$ productivity. Although this study had small sample size, the findings showed benefit of ARV treatment on productivity loss.

Figure 2. Percent productivity increasing, stable, and decreasing of severe liver disease group with and without ARV

Abbreviation: ARV, antiviral therapy for hepatitis $\mathrm{B}$ infection, $\mathrm{CHB}$, chronic hepatitis B, HBsAg, hepatitis B surface antigen, HCC, hepatocellular carcinoma, $\mathrm{LF}$, liver function

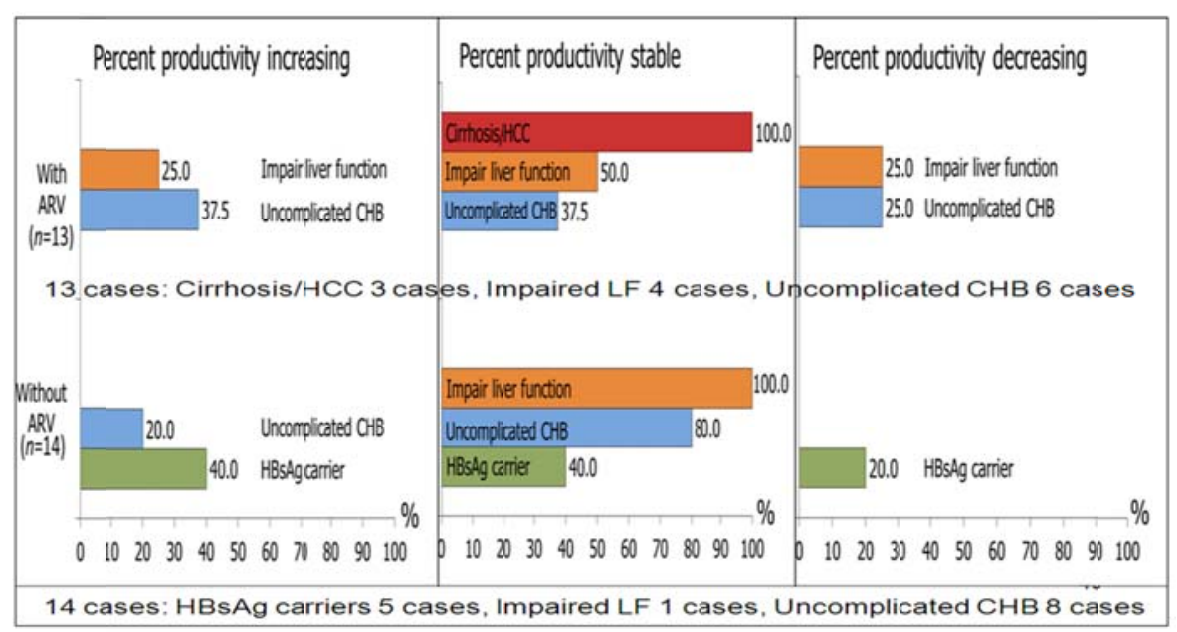

\section{Discussion}

In this study, the non-severe liver disease group had 10.5\% lost follow up during the first 6 months. This might be because these patients were referred from antenatal care, health checkups, and blood donation service for testing liver function test without any illness, and most of them had normal laboratory tests, so they might not be aware to maintain a regular monitoring or continue hospital care. In contrast, patients with severe liver disease had $13.1 \%$ loss follow up at $12^{\text {th }}$ month. It might be that the patients got better after 6 months of treatment without having knowledge and awareness of regular monitoring. Several studies have demonstrated that hepatitis B patients have poor knowledge, attitude and practice towards their diseases ${ }^{[15,16]}$. It was stressed that one of the most dangerous aspects of the HBV virus is that most people do not realize they have been infected. This should be considered that there must have been those with poorer status who did not know their HBV status, and never received investigations. In addition, during the study, some patients informed that their co-workers have known their hepatitis B positive but not recognized for investigations. Therefore, health promotions for regular monitoring are needed for hepatitis B patients.

This is the first study that assessed CLDQ in CHB patient over time. CHB patients had health impairments that need clinical management. In patients with severe liver disease, physical illness affects their worry and emotional functions reflected by their CLDQ. These findings showed that anxiety or worry did not narrate with any symptoms because these aspects were based on patients' perception. Over time, the severe liver disease group had CLDQ score increasing specifically in emotional function and worry domains as shown in Figure 1. This information showed that CHB patients with severe liver disease need clinical care, regular liver function test monitoring, and specific counseling program to manage their physical and psychological illness.

The direct medical cost of CHB patients in the present study was quite low when compared to the studies in China ${ }^{[3,4]}$ because this is a cost approach with case by case database study. However, there are several advantages of doing costs in this study. First, the annual cost including the drug cost, laboratory and radiology cost were collected in each patient form 
the hospital information database that should be more accurate than an average cost based from the national database or a predicted cost from the model. Unlike, most of the previous studies where retrospective analysis, used a model that may result in gross magnification of errors ${ }^{[16]}$, and most studies were analyzed based on the perspectives of health care system or third party payer which considered only direct medical costs ${ }^{[17]}$. Second, the work on productivity loss over time was assessed and it could reflect productivity loss of employer or society. Finally, information from this study is essential and beneficial for further analysis on economic appraisals for CHB management.

CHB-related diseases could result to productivity loss especially in patients with cirrhosis. This is the first study that measured work-related disorders in CHB patients that could express productivity loss in monetary value. It provides an understanding of a considerable indirect cost of the CHB patients to the society. In this study, the productivity loss rated in patients' perspective was approximately $10 \%$, and could be more if the disease progress to cirrhosis. This may be related to impairment of physical and psychological function. The findings have shown that patients with cirrhosis and HCC had work loss and died at a one-year follow up even if these patients were already treated. This finding highlighted the importance of prevention of the CHB patient from developing cirrhosis.

Over time, CHB patients with ARV for hepatitis B infection had productivity increasing or indirect cost reducing, accept for the patients with cirrhosis and HCC. These patients tended to have work loss and died because the natural progression of HBV is associated with an increased morbidity and mortality ${ }^{[2,18]}$. This study showed that ARV benefits the noncirrhosis CHB patients ${ }^{[19]}$. Also, previous economic analyses have shown the cost-effectiveness of ARV in CHB patient ${ }^{[19-22]}$ that could save direct medical costs from progressive liver damages ${ }^{[4]}$. In addition, in severe CHB cases, the finding showed that ARV cost was less than indirect cost (mean (SD) ARV cost $=$ USD 490.4 (861.3), indirect cost $=$ USD 584.2 (797.0)). Hence, this finding emphasized the importance of early ARV treatment on indirect costs and health impairments of CHB patient that should be considered.

\section{Acknowledgement}

The authors would like to thank the Faculty of Tropical Medicine and the Clinical Infectious Diseases Research Unit, Mahidol University for the funding, Professor Emeritus Chaivej Nuchprayoon for his guidance and comments, and all staff at Queen Savang Vadhana Memorial Hospital for their kind supports.

\section{References}

[1] Lavanchy D. Worldwide epidemiology of HBV infection, disease burden, and vaccine prevention. Journal of clinical virology. 2005; 34(Suppl.1): S1-S3. http://dx.doi.org/10.1016/S1386-6532(05)00384-7

[2] Lok ASF, McMahon BJ. Chronic hepatitis B; AASLD practice guidelines. Hepatology. 2007; 45: 507-539. PMid:17256718 http://dx.doi.org/10.1002/hep.21513

[3] Lu J, Xu A, Wang J, Zhang L, Song L, Li R, et al. Direct economic burden of hepatitis B virus related diseases: evidence from Shandong, China. BMC Health Services Research. 2013; 13: 37. PMid:23368750 http://dx.doi.org/10.1186/1472-6963-13-37

[4] $\mathrm{Hu} \mathrm{M}$, Chen W. Assessment of total economic burden of Chronic Hepatitis B (CHB)-related diseases in Beijing and Guangzhou, China. Value Health. 2009; 12(Suppl3): S89-92. PMid:20586991 http://dx.doi.org/10.1111/j.1524-4733.2009.00636.x

[5] Liang S, Zhang SX, Ma QS, Xiao HW, Lü QY, Xie X, et al. Financial burden of hepatitis B-related diseases and factors influencing the costs in Shenzhen, China. Zhonghua Liu Xing Bing Xue Za Zhi. 2010; 31(12): 1340-1345. PMid:21223660

[6] Li SC, Ong SC, Lim SG, Yeoh KG, Kwong KS, Lee V, et al. A cost comparison of management of chronic hepatitis B and its associated complications in Hong Kong and Singapore. J ClinGastroenterol. 2004; 38(10 Suppl 3): S136-43. PMid:15602161 http://dx.doi.org/10.1097/00004836-200411003-00004

[7] Yang BM, Kim CH, Kim JY. Cost of chronic hepatitis B infection in South Korea. J ClinGastroenterol. 2004; $38(10$ Suppl 3):S153-7. PMid:15602164 http://dx.doi.org/10.1097/00004836-200411003-00007

[8] Ott JJ, Stevens GA, Groeger J, Wiersma ST. Global epidemiology of hepatitis B virus infection: New estimates of age-specific HBsAg sero prevalence and endemicity. Vaccine. 2012; 30: 2212-2219. PMid:22273662

http://dx.doi.org/10.1016/j.vaccine.2011.12.116 
[9] Liver Society (Thailand). Thailand Consensus Recommendations for Management of Chronic Hepatitis B and C 2009. Bangkok: Liver Society (Thailand); 2010.

[10] McMahon BJ. Natural history of chronic hepatitis B. Clin Liver Dis. 2004; 14: 381-396. PMid:20638020 http://dx.doi.org/10.1016/j.cld.2010.05.007

[11] Di Macro V. Chronic hepatitis B: Do we know everything or is there still something to learn?. Digestive and Liver Disease Suppl. 2009; 3: 61-66. http://dx.doi.org/10.1016/S1594-5804(09)60024-3

[12] Sobhonslidsuk A, Silpakit C, Konsakon R, Satitpornkul P, Sripetch C. Chronic liver disease questionnaire: Translation and validation in Thais. World J Gastroenterol. 2004; 10(13): 1954-1957. PMid:15222044

[13] Wongpaitoon, V. Hepatitis B Threat Grows for Millions in Thailand and Asia. Better Health. $2008 ; 1$.

[14] Younossi ZM, Guyatt G. Quality-of-life assessments and chronic liver disease. Am J Gastroenterol. 1998; 93: 1037-1041. PMid:9672326 http://dx.doi.org/10.1111/j.1572-0241.1998.00325.x

[15] Ul Hag N, Hassali MA, Shafie AA, Saleem F, Farooqui M, Haseeb A et al. A cross-sectional assessment of knowledge, attitude and practice among Hepatitis-B patients in Quetta, Pakistan. BMC Public Health. 2013; 13: 448. PMid:23641704 http://dx.doi.org/10.1186/1471-2458-13-448

[16] Nguyen TT, Taylor V, Chen MS Jr, Bastani R, Maxwell AE, McPhee SJ. Hepatitis B awareness, knowledge, and screening among Asian Americans. J Cancer Educ. 2007; 22(4): 266-72. PMid:18067441 http://dx.doi.org/10.1007/BF03174128

[17] Dan YY, Aung MO, Lim SG. The economics of treating chronic hepatitis B in Asia. Hepatol Int. 2008;2:284-295.PMid:19669256 http://dx.doi.org/10.1007/s12072-008-9049-2

[18] Tantai N, Chaikledkaew1 U. Werayingyong P. Teerawattananon Y. Economic Evaluation of Drug Treatments for Patients with Chronic Hepatitis B (CHB): Results from a Systematic Review. Mahidol University Journal of Pharmaceutical Science. 2010; 37(3-4): 37-45.

[19] Kanwal F, Hays RD, Kilbourne AM, Dulai GS, Gralnek IM. Are physician-derived disease severity indices associated with health-related quality of life in patients with end-stage liver disease?. Am J Gastroenterol. 2004; 99: 1726-1732. PMid:15330910 http://dx.doi.org/10.1111/j.1572-0241.2004.30300.x

[20] Buti M, Brosa M, Casado MA, Rueda M, Esteban R. Modeling the cost-effectiveness of different oral antiviral therapies in patients with chronic hepatitis B. Journal of Hepatology. 2009; 51: 640-646. PMid:19576651 http://dx.doi.org/10.1016/j.jhep.2009.04.013

[21] Choi MS, Yoo BC. Management of chronic hepatitis B with nucleoside or nucleotide analogues: A review of current guidelines. Gut and Liver. 2010; 4(1): 15-25. PMid:20479908http://dx.doi.org/10.5009/gnl.2010.4.1.15

[22] Kanwal F, Hays RD, KilbourneAM, Dulai GS, Gralnek IM. Are physician-derived disease severity indices associated with health-related quality of life in patients with end-stage liver disease?.Am J Gastroenterol. 2004; 99: 1726-1732. PMid:15330910 http://dx.doi.org/10.1111/j.1572-0241.2004.30300.x 